\title{
Alternaria yaliinficiens sp. nov. on Ya Li Pear Fruit: From Interception to Identification
}

\author{
Rodney G. Roberts, United States Department of Agriculture-Agricultural Research Service, Tree Fruit Research \\ Laboratory, Wenatchee, WA 98801
}

\begin{abstract}
Roberts, R. G. 2005. Alternaria yaliinficiens sp. nov. on Ya Li pear fruit: From interception to identification. Plant Dis. 89:134-145.

In 2001, numerous Ya Li pear fruit from China with a disease apparently caused by an Alternaria sp. were intercepted at U.S. ports, raising concern because the disease was unknown in the United States. To identify the etiologic agent of the disease, single-spore cultures were established from intercepted fruit and were characterized by pathogenicity to wounded fruit, morphology, and sporulation pattern on three agar media, random amplified polymorphic DNA fragment pattern analysis, and species-specific polymerase chain reaction (PCR). These data indicated that the disease likely was caused by more than one species of Alternaria, and that none of the isolates from intercepted Ya Li fruit was A. alternata or A. gaisen. A species-specific PCR assay for A. gaisen demonstrated that no isolate from Ya Li was A. gaisen. A PCR assay for the AMT gene demonstrated that no isolate from Ya Li was A. 'mali'. Because of these data and the absence of a description to accommodate at least one of the taxa involved, A. yaliinficiens $\mathrm{R}$. G. Roberts sp. nov. is described, and the disease caused by this and other species of Alternaria on Ya Li pear from China is referred to as "chocolate spot of Ya Li pear" to distinguish it from black spot of Japanese pear.
\end{abstract}

Additional keywords: citrus, host-specific, pathotype, toxin

In the early 1990s, China began to export fruit of Ya Li pear (Pyrus bretschneideri Rehd. cv. Ya Li) from Hebei province to several countries, including Australia, Canada, New Zealand, and the United States. Ya Li pear exports from China to the United States began in 1995 and, in 2001, many Ya Li pear fruit with a disease apparently caused by an Alternaria sp. were intercepted by personnel of the United States Department of Agriculture (USDA) Animal and Plant Health Inspection Service (APHIS) at multiple ports of entry. Between 12 October 2001 and 2 March 2002, 37 shipments of Ya Li pear fruit imported from China (hereafter referred to as "Chinese Ya Li pear") were rejected or re-exported because of symptoms and sign of Alternaria spp. infection. Imports of Chinese $\mathrm{Ya} \mathrm{Li}$ pear into the United States were suspended in March 2002 because of the interception of another

Corresponding author: R. G. Roberts

E-mail: roberts@tfrl.ars.usda.gov

Accepted for publication 9 September 2004.

DOI: 10.1094/PD-89-0134

This article is in the public domain and not copyrightable. It may be freely reprinted with customary crediting of the source. The American Phytopathological Society, 2005. pest of phytosanitary concern, the Fusicladium anamorph of the pear scab pathogen Venturia nashicola Tanaka \& Yamamoto. The U.S. program to import Chinese Ya Li pear fruit has been suspended each year since the 2001-2002 season due to repeated interceptions of the Alternaria spp. disease. Interceptions of similarly decayed Chinese $\mathrm{Ya} \mathrm{Li}$ pear fruit were noted in 2001 by plant quarantine authorities in Australia, New Zealand, and the United Kingdom, although the first known Canadian interceptions of Chinese $\mathrm{Ya} \mathrm{Li}$ pear fruit infected by Alternaria spp. occurred as early as 1993 . The widespread export of this pear cultivar from China and the high incidence of interceptions by importing countries of this Alternaria spp. disease have generated persistent scientific, regulatory, and economic interest in the accurate identification of the etiologic agent or agents of the Ya Li disease.

This import program was initiated under a regulatory process consistent with Article 5 of the Agreement on Sanitary and Phytosanitary Measures (SPS) (26) that included a 1994 pest risk assessment (PRA) by the United States for multiple pear pests, the names of which were provided in part to the United States by Chinese plant quarantine officials. The PRA was revised in 1997 due, in part, to the necessary inclusion of several new pest species not ad- dressed by the original PRA. Two species of Alternaria, A. alternata (Fr.) Keissler and $A$. gaisen Nagano, were included in the 1997 revised PRA: A. alternata as a nonquarantine pest that would be expected to remain with the commodity during processing and shipping, and A. gaisen as a quarantine pest (4).

Although fungal diseases of both Chinese and Japanese pear have been of interest to phytopathologists and mycologists since the early twentieth century, there are no reports documenting the fungal pathogens of Ya Li pear from China that make it possible to determine the identity of the Alternaria taxa associated with the disease. Unfortunately, the most recent information from Chinese sources, both governmental and academic, has not provided consensus regarding either the Alternaria spp. that occur on Ya Li fruit in China or the etiologic agent of the disease on exported fruit. Recent references to Alternaria spp. occurring on Ya Li pear include a pest list published in 1994 (2) and a recently published book on Alternaria spp. in China by Prof. T. Y. Zhang (27). The cultivars included in the pest list include $P$. bretschneideri, $P$. serotina Rehd., $P$. ussuriensis Max., and $P$. communis L. The only species of Alternaria reported in this list on fruit is $A$. alternata in Sichuan and Jiangsu provinces. A. bokurai Miura is listed on leaves from Jilin, Liaoning, Shandong, Henan, Qinghai, Jiangsu, Zhejiang, and Guangdong provinces and Taiwan. A. kikuchiana Tanaka is listed on leaves from Jilin, Shanxi, Liaoning, Shandong, Henan, Qinghai, Jiangsu, Zhejiang, Guangxi, and Guangdong provinces. A. mali Roberts is listed on leaves from Liaoning and $\mathrm{Si}$ chuan provinces. Zhang (27) listed A. alternata on $P$. communis in Xiangshan, Beijing, and Hebei Provinces; A. tenuissima (Fr.) Wiltshire from Pyrus sp., in Jinan, Shandong, Shijiazhuang, and Hebei provinces; and A. gaisen from Pyrus sp. in Guangdong, Hebei, Henan, Jiangsu, Liaoning, Jilin, Qinghai, Shandong, Shanxi, Shijiazhuang, and Zhejiang provinces, Guangxi and Xinjiang Autonomous Regions, and Taiwan. A. gaisen also is listed on P. ussuriensis Maxim. from Jilin province and on $P$. pyrifolia (Brum.) Nakai from Zhejiang province. Finally, Zhang (27) provides reference to a report of 
A. mali on P. calleryana Decne. from Sichuan province.

Problematic issues surrounding most of the Alternaria names mentioned above prohibit their ready application to specimens of phytosanitary interest. First and foremost is the name A. alternata, for which the misapplication and misidentification by plant pathologists has all but eliminated the predictive value associated with the nomenclatural type $(15,16,27)$ and has rendered the phytopathological literature of the past 25 years nearly meaningless to all true students of the genus and diagnosticians alike. This is an especially onerous and damaging result for regulatory phytopathologists and mycologists, who are charged with the protection of plant health and agriculture in their home countries and who must make accurate identifications from intercepted materials to prevent the introduction of exotic plant pathogens. The practical outcome of decades of misapplication of the name A. alternata is that all literature references to and identifications of living cultures as $A$. alternata must be investigated carefully and confirmed before they can be accepted as valid, and that, in the interim, the most reasonable assumption is that such reports are in error.

Limitations to the application of the name $A$. bokurai have been discussed previously by Simmons (17) and Zhang (27). Miura (10) used the name A. bokurai for the incitant of "ring spot disease" of Chinese pear, and listed the earlier, validly published name A. gaisen as a synonym. Simmons (17) noted, therefore, that the name A. bokurai is illegitimate in terms of the International Code of Botanical Nomenclature (6) and that, because neither a description nor specimen of the fungus from Miura or Bokura could be found, $A$. bokurai could not be evaluated within the context of his nomenclatural and morphological investigations of A. gaisen. Being illegitimate, the name $A$. bokurai cannot be applied correctly to any fungus. Simmons did note that, after Tanaka examined the morphological and pathological characters (symptoms and pathogenicity) of the $\mathrm{Al}$ ternaria sp. from Chinese pear fruit sent to him by Miura, Tanaka concluded that the Alternaria pathogens of Chinese (A. bokurai) and Japanese (A. gaisen, as A. kikuchiana) pear were different species (22). Zhang's later comments on A. bokurai (27) regarding the lack of authentic material for study essentially follow Simmons (17); therefore, the uncertainty surrounding the application of the name $\mathrm{A}$. bokurai to $\mathrm{Al}$ ternaria pathogens of Chinese pear persists.

A. kikuchiana Tanaka is a synonym of $A$. gaisen (17), and will not be discussed further here, other than to note that A. gaisen does not occur in the United States and is considered a quarantine pest. Simmons (19) noted that A. mali suffers from the same mistreatment at the hands of plant pathologists as does $A$. alternata. The name $A$. mali has been and currently is applied to the perthotrophic apple leaf pathogens that produce putative host-specific toxins, in spite of Roberts' description of A. mali as being a "strong facultative parasite" (14).

In spite of the Chinese records of various species of Alternaria mentioned above from specimens of $\mathrm{Ya} \mathrm{Li}$ pear grown in China, Chinese plant quarantine officials responded to the first interceptions in 2001 by asserting that $A$. alternata was the only pathogen associated with $\mathrm{Ya} \mathrm{Li}$ pear in China and, because A. alternata is considered to be cosmopolitan, no regulatory action was warranted because of the Alternaria sp. disease (Zhang Li to D. Maki, USDA-APHIS, Jan 2002, official correspondence). Within this context, this article documents the process and results of studies during 2001-02 to identify the etiologic agent or agents causing decay of $\mathrm{Ya} \mathrm{Li}$ pear fruit imported from China.

\section{MATERIALS AND METHODS}

Isolation, culture, and pathogenicity. All intercepted Chinese Ya Li pear fruit received at the USDA-ARS Tree Fruit Research Laboratory, Wenatchee, WA in 2001 bore visible lesions and usually sporulation of Alternaria spp. Single-spore cultures were established from each fruit by touching an inoculating loop to a lesion and then streaking the loop onto $2 \%$ water agar to physically separate conidia. Individual conidia then were picked from the agar surface under stereoscopic magnification using a finely drawn glass needle and transferred to potato carrot agar (PCA; 20). Isolates obtained in 2001 from Chinese $\mathrm{Ya} \mathrm{Li}$ pear and other reference isolates of interest are listed in Table 1. Isolates were maintained as small (approximately 3- to 4-mm) agar blocks cut from the leading edge of a PCA culture and stored in water at $4^{\circ} \mathrm{C}$.

Pathogenicity of isolates selected from Ya Li intercepts and other species of interest, including A. alternata and A. gaisen, was evaluated by wound inoculation of commercially obtained Chinese Ya Li pear. After swabbing fruit surfaces with $70 \%$ ethanol, inoculation sites were punctured with a dissecting needle bearing conidia from a PCA culture, one fruit per isolate per each of two trials. Inoculated fruit and negative controls (punctured but without transfer of conidia) were held at room temperature under cool white fluorescent lights in a plastic bin covered with polyethylene film and a cycle of $8 \mathrm{~h}$ light, $16 \mathrm{~h}$ dark for 14 days. Koch's postulates were fulfilled by confirming the reisolation of the strains used for inoculation.

For morphological examination, each isolate was grown on Hay, V8 juice, PCA, and half-strength PCA agars, and morphological characters were observed by meth- ods previously reported (20). Particular attention was paid to sporulation pattern and conidial characters, because both $A$. gaisen and A. alternata are among many species that have been shown to exhibit recognizable, predictive, and diagnostic patterns of sporulation under the conditions referenced above.

Molecular analysis. Analysis of fragment patterns from random amplified polymorphic DNA (RAPD; 24,25) of Alternaria isolates from Chinese $\mathrm{Ya} \mathrm{Li}$ pear was conducted by methods described by Roberts et al. (15), and included selected fragment patterns of isolates from an existing database of more than 400 Alternaria isolates. Polymerase chain reaction (PCR) primers specific for A. gaisen were designed using GeneCompar (Applied Maths, Ghent, Belgium) and the nucleotide sequence for AKT-1, a biosynthetic gene necessary for production of a phytotoxin by $A$. gaisen (often referred to by the nomenclaturally baseless name "A. alternata Japanese pear pathotype") as obtained from GenBank (accession number AB015351; 21). The primer pair gaif2 (5'-AACGATTTCGACAAAGCTCT-3') and gair2 (5'AGATGTTTGCCAGG-GGAATT-3'), anneal to bases 604 to 623 and to the compliment of bases 831 to 850 of the AKT-1 sequence, respectively, and produce a 247 bp amplicon.

Gaif2/gair2 was screened for specificity against 194 Alternaria isolates from various hosts and geographic origins (Table 2) in $50-\mu \mathrm{l}$ reaction mixtures containing $8 \mathrm{ng}$ of template, $2 \mathrm{mM} \mathrm{MgCl} 2,50 \mathrm{mM} \mathrm{KCl}, 10$ $\mathrm{mM}$ Tris $\mathrm{HCl}(\mathrm{pH} 8.3), 200 \mu \mathrm{mol}$ of each dNTP, 25 pmol of each primer, and 1 unit of Taq polymerase. Each reaction mixture also contained the $\beta$-tubulin primers $\beta$ tub1 and $\beta$-tub2 (7) as internal controls to verify that PCR-conducive conditions and suitable template were present during screening reactions. Thermal cycling conditions were initial denaturation at $94^{\circ} \mathrm{C}$ for $5 \mathrm{~min}$ followed by 40 cycles of denaturation at $94^{\circ} \mathrm{C}$ for $30 \mathrm{~s}$, annealing at $62^{\circ} \mathrm{C}$ for $30 \mathrm{~s}$, and extension at $72^{\circ} \mathrm{C}$ for $1 \mathrm{~min}$, with a final extension at $72^{\circ} \mathrm{C}$ for $5 \mathrm{~min}$. All Alternaria isolates obtained from intercepted Ya Li pear fruit were evaluated for the presence of the AKT-1 gene by this method. Additionally, all Alternaria isolates from Ya Li pear and others in Table 1 were evaluated for the presence of the AMT (A. 'mali' toxin) gene according to the method of Johnson et al. (7).

\section{RESULTS}

Pathogenicity. All Alternaria isolates from Chinese Ya Li pear used in pathogenicity experiments produced lesions on wound-inoculated $\mathrm{Ya} \mathrm{Li}$ pear fruit (Fig. 1A) typical of naturally occurring lesions on intercepted fruit (Fig. 1B) Lesions developed rapidly at room temperature, and enlarged from approximately 2 to $5 \mathrm{~cm}$ at 7 days to approximately 5 to $8 \mathrm{~cm}$ by 14 
days (Fig. 1A). All isolates of other species used to inoculate wounded Chinese $\mathrm{Ya} \mathrm{Li}$ pear fruit also produced expanding lesions, except RGR 91.0091 (Tottori 15A) (Fig. 1 ), the standard isolate of $A$. gaisen from Japan upon which much of the AKT phytotoxin work has been done (23). Other isolates of A. gaisen from Korea (RGR 91.0086) and Taiwan (RGR 91.0070) produced lesions, but lesion margins were pale, reddish brown, and differed from those produced by all other species tested (dark, chocolate brown). The mycelium that grew from lesions caused by A. gaisen was grayer and more floccose than that observed on lesions caused by other Alternaria isolates from pear (Fig. 1: group 1, Japan and Alt. sp.), which produced a relatively low, dense, dark green to black turf of sporulation, with little initial visible mycelial growth. The standard isolates of A. alternata (RGR 91.0102, RGR 91.0128, and RGR 91.0066) also produced lesions that varied in appearance by isolate. The lesions produced by $A$. alternata were somewhat similar in appearance to those produced by isolates obtained from infected $\mathrm{Ya} \mathrm{Li}$ pear, although the lesion margins produced by $A$. alternata tended to be broader than those produced by isolates from Chinese Ya Li pear. The group 1 (20) isolates from Japanese pear produced lesions that were nearly identical to those produced by isolates from $\mathrm{Ya} \mathrm{Li}$ pear.

A box of Chinese Ya Li pear fruit was purchased from a wholesale distributor and, when first opened, nearly every pear exhibited symptoms of Alternaria sp. in- fection at the stem end (Fig. 1A, C, and D). These stem lesions were dark brown to black, shiny in appearance, and were associated with the progressive collapse of the stems as the infection progressed toward the fruit. The fruit were incubated during inoculation experiments or held in cold storage; therefore, the margins of these lesions eventually reached the fruit cortex and then rapidly developed into a stem-end fruit decay (Fig. 1D) typical of that observed on intercepted Chinese Ya Li pear with Alternaria sp. lesions (Fig. 1B).

Naturally occurring lesions observed on Chinese $\mathrm{Ya} \mathrm{Li}$ pear varied in having smooth to irregular margins, and a zonate appearance often was evident until the lesion surface was occluded by sporulation. Lesions were seen at the calyx ends

Table 1. Isolates studied in 2001 during efforts to identify the Alternaria spp. associated with intercepted Chinese Ya Li pear fruit ${ }^{\mathrm{a}}$

\begin{tabular}{|c|c|c|c|c|c|c|c|}
\hline Isolate no. & Name or other referring no. & Origin & Host & $\begin{array}{c}\text { Pathogenic to } \\
\text { Ya Li fruit }\end{array}$ & $\begin{array}{l}\text { RAPD analysis } \\
\text { completed }\end{array}$ & gaif2-r2 & AMT \\
\hline RGR 01.0185 & sp. & China & Ya Li pear & + & + & - & - \\
\hline RGR 01.0186 & sp. & China & Ya Li pear & + & + & - & - \\
\hline RGR 01.0187 & sp. & China & Ya Li pear & ND & + & - & - \\
\hline RGR 01.0188 & sp. & China & Ya Li pear & ND & + & - & - \\
\hline RGR 01.0189 & sp. & China & Ya Li pear & + & + & - & - \\
\hline RGR 01.0190 & sp. & China & Ya Li pear & ND & + & - & - \\
\hline RGR 01.0191 & sp. & China & Ya Li pear & ND & + & - & - \\
\hline RGR 01.0192 & sp. & China & Ya Li pear & ND & + & - & - \\
\hline RGR 01.0194 & sp. & China & Ya Li pear & ND & + & - & - \\
\hline RGR 01.0195 & sp. & China & Ya Li pear & ND & + & - & - \\
\hline RGR 01.0196 & sp. & China & Ya Li pear & ND & + & - & - \\
\hline RGR 01.0197 & sp. & China & Ya Li pear & ND & + & - & - \\
\hline RGR 01.0198 & sp. & China & Ya Li pear & ND & + & - & - \\
\hline RGR 01.0199 & sp. & China & Ya Li pear & + & + & - & - \\
\hline RGR 01.0200 & sp. & China & Ya Li pear & ND & + & - & - \\
\hline RGR 01.0201 & sp. & China & Ya Li pear & ND & + & - & - \\
\hline RGR 01.0202 & sp. & China & Ya Li pear & ND & + & - & - \\
\hline RGR 01.0203 & sp. & China & Ya Li pear & + & + & - & - \\
\hline RGR 01.0204 & A. yaliinficiens & China & Ya Li pear & + & + & - & - \\
\hline RGR 01.0205 & sp. & China & Ya Li pear & ND & + & - & - \\
\hline RGR 01.0206 & sp. & China & Ya Li pear & + & + & - & - \\
\hline RGR 01.0207 & sp. & China & Ya Li pear & + & + & - & - \\
\hline RGR 01.0208 & sp. & China & Ya Li pear & + & + & - & - \\
\hline RGR 01.0209 & sp. & China & Ya Li pear & ND & + & - & - \\
\hline RGR 01.0210 & sp. & China & Ya Li pear & + & + & - & - \\
\hline RGR 91.0091 & A. gaisen, EGS 37.1321, Tottori 15A & Japan & Japanese pear & - & + & + & - \\
\hline RGR 91.0070 & A. gaisen, EGS 38.1561 & Taiwan & Japanese pear & + & + & + & - \\
\hline RGR 91.0089 & A. gaisen, EGS 39.0030 & Korea & Japanese pear & + & + & + & - \\
\hline RGR 91.0102 & A. alternata, EGS 34.016 & India & Leguminosae & + & + & - & - \\
\hline RGR 91.0066 & A. alternata, EGS 35.056 & India & Malvaceae & + & + & - & - \\
\hline RGR 91.0073 & Group 1, EGS 90.0522 & Japan & Japanese pear & + & + & - & - \\
\hline RGR 91.0206 & Group 1, EGS 90.0161 & Japan & Japanese pear & + & + & - & - \\
\hline RGR 91.0107 & Group 1, EGS 90.0991 & Japan & Japanese pear & + & + & - & - \\
\hline RGR 92.0021 & A. arbusti, EGS 91.1320 & United States & Japanese pear & ND & + & - & - \\
\hline RGR 92.0014 & A. arbusti, EGS 91.1290 & United States & Japanese pear & ND & + & - & - \\
\hline RGR 92.0009 & A. arbusti, EGS 91.1360 & United States & Japanese pear & ND & + & - & - \\
\hline RGR 96.0145 & A. longipes, EGS 30.149 & United States & Tobacco & ND & + & - & - \\
\hline RGR 96.0146 & A. longipes, EGS 30.048 & United States & Tobacco & ND & + & - & - \\
\hline RGR 96.0152 & A. longipes, EGS 30.034 & United States & Tobacco & ND & + & - & - \\
\hline RGR 91.0173 & A. arborescens, EGS 90.0690 & Japan & Japanese pear & ND & + & - & - \\
\hline RGR 91.0017 & A. arborescens, EGS 90.1071 & Japan & Japanese pear & ND & + & - & - \\
\hline RGR 97.0070 & arborescens grp & United States & Apple, fruit & ND & + & - & - \\
\hline RGR 99.0128 & A. arborescens, EGS 39.128 & United States & Tomato & ND & + & - & - \\
\hline RGR 92.0024 & arborescens grp, EGS 91.0890 & United States & Japanese pear & ND & + & - & - \\
\hline RGR 92.1543 & tenuissima group & United States & Cherry fruit & ND & + & - & - \\
\hline RGR 92.1727 & tenuissima group & United States & Cherry fruit & ND & + & - & - \\
\hline RGR 96.0027 & A. tenuissima, EGS 33.200 & United States & Onion & ND & + & - & - \\
\hline RGR 01.0023 & sp., 540 ex C.F. Lane, UK & China & Chinese pear & ND & + & - & - \\
\hline RGR 01.0026 & sp., VPRI 22756, I. Pascoe, AUS & China & Chinese pear & ND & + & - & - \\
\hline
\end{tabular}

\footnotetext{
a Positive result indicated by + , except for the random amplified polymorphic DNA (RAPD) column, where + indicates that RAPD fragments were analyzed;
} $\mathrm{ND}=$ not determined; $-=$ negative result. 
Table 2. Alternaria isolates used to verify specificity of Alternaria gaisen-specific polymerase chain reaction primers

\begin{tabular}{|c|c|c|c|}
\hline Isolate no. & Alternaria sp. & Host, substrate & Origin \\
\hline RGR 01.0006 & 'mali' & Malus domestica & United States \\
\hline RGR 01.0007 & 'mali' & M. domestica & United States \\
\hline RGR 01.0008 & 'mali' & M. domestica & United States \\
\hline RGR 01.0009 & sp. & Pyrus sp. & Argentina \\
\hline RGR 01.0010 & gaisen & Pyrus pyrifolia & Korea \\
\hline RGR 01.0011 & 'mali' & M. domestica & United States \\
\hline RGR 01.0012 & 'mali' & M. domestica & United States \\
\hline RGR 01.0013 & 'mali' & M. domestica & United States \\
\hline RGR 01.0014 & sp. & P. communis & Portugal \\
\hline RGR 01.0015 & 'mali' & M. domestica & United States \\
\hline RGR 01.0016 & 'mali' & M. domestica & United States \\
\hline RGR 01.0017 & 'mali' & M. domestica & United States \\
\hline RGR 01.0018 & 'mali' & M. domestica & United States \\
\hline RGR 01.0019 & 'mali' & M. domestica & United States \\
\hline RGR 01.0020 & sp. & Triticum sp. & Unknown \\
\hline RGR 01.0021 & sp. & P. communis & Portugal \\
\hline RGR 01.0022 & 'mali’ & M. domestica & United States \\
\hline RGR 01.0023 & sp. & Pyrus (bretschneideri?) & China \\
\hline RGR 01.0181 & limicola & Citrus aurantifolia & Mexico \\
\hline RGR 87.0031 & 'mali' & M. domestica & Japan \\
\hline RGR 91.0066 & alternata & Leguminosae & India \\
\hline RGR 91.0070 & gaisen & Pyrus pyrifolia & Taiwan \\
\hline RGR 91.0074 & gaisen & P. pyrifolia & Taiwan \\
\hline RGR 91.0075 & gaisen & P. pyrifolia & Japan \\
\hline RGR 91.0076 & gaisen & P. pyrifolia & Japan \\
\hline RGR 91.0079 & gaisen & P. pyrifolia & Japan \\
\hline RGR 91.0081 & gaisen & P. pyrifolia & Japan \\
\hline RGR 91.0084 & gaisen & P. pyrifolia & Taiwan \\
\hline RGR 91.0086 & gaisen & P. pyrifolia & Korea \\
\hline RGR 91.0089 & gaisen & $P$. pyrifolia & Korea \\
\hline RGR 91.0090 & gaisen & P. pyrifolia & Japan \\
\hline RGR 91.0091 & gaisen & P. pyrifolia & Japan \\
\hline RGR 91.0092 & gaisen & P. pyrifolia & Japan \\
\hline RGR 91.0098 & gaisen & P. pyrifolia & Japan \\
\hline RGR 91.0101 & gaisen & P. pyrifolia & Japan \\
\hline RGR 91.0102 & alternata & Datura metel & India \\
\hline RGR 91.0109 & gaisen & P. pyrifolia & Japan \\
\hline RGR 91.0110 & gaisen & P. pyrifolia & Japan \\
\hline RGR 91.0119 & gaisen & P. pyrifolia & Japan \\
\hline RGR 91.0122 & gaisen & P. pyrifolia & Japan \\
\hline RGR 91.0123 & gaisen & P. pyrifolia & Japan \\
\hline RGR 91.0125 & gaisen & P. pyrifolia & Japan \\
\hline RGR 91.0127 & gaisen & P. pyrifolia & Japan \\
\hline RGR 91.0128 & alternata & Musaceae & India \\
\hline RGR 91.0129 & alternata & Malvaceae & India \\
\hline RGR 91.0136 & gaisen & P. pyrifolia & Japan \\
\hline RGR 91.0154 & sp. & P. pyrifolia & Michigan, United States \\
\hline RGR 91.0156 & gaisen & P. pyrifolia & Japan \\
\hline RGR 91.0159 & gaisen & P. pyrifolia & Japan \\
\hline RGR 91.0161 & sp. & P. pyrifolia & Japan \\
\hline RGR 91.0163 & gaisen & P. pyrifolia & Japan \\
\hline RGR 91.0164 & gaisen & P. pyrifolia & Japan \\
\hline RGR 91.0166 & gaisen & P. pyrifolia & Japan \\
\hline RGR 92.0007 & sp. & M. domestica & Japan \\
\hline RGR 92.0008 & sp. & M. domestica & Japan \\
\hline RGR 92.0009 & arbusti & P. pyrifolia & California, United States \\
\hline RGR 92.0011 & sp. & M. domestica & Japan \\
\hline RGR 92.0017 & sp. & M. domestica & Japan \\
\hline RGR 92.0019 & sp. & M. domestica & Japan \\
\hline RGR 94.0115 & 'mali' & M. domestica & Louisiana, United States \\
\hline RGR 94.0116 & 'mali' & M. domestica & Louisiana, United States \\
\hline RGR 94.0146 & 'mali' & M. domestica & Louisiana, United States \\
\hline RGR 96.0009 & triticina & Triticum aestivum & India \\
\hline RGR 96.0013 & incomplexa & Limo fluviali & Idaho, United States \\
\hline RGR 96.0017 & infectoria & T. aestivum & United Kingdom \\
\hline RGR 96.0028 & tenuissima & Dianthus sp. & United Kingdom \\
\hline RGR 96.0035 & angustiovoidea & Euphorbia esula & Manitoba, Canada \\
\hline RGR 96.0036 & helianthinficiens & Helianthus annuus & South Dakota, United States \\
\hline RGR 96.0042 & metachromatica & T. aestivum & Australia \\
\hline RGR 96.0052 & tropica & Passiflora edulis & FL, USA \\
\hline RGR 96.0054 & cyphomandrae & Cyphomandra betacea & New Zealand \\
\hline RGR 96.0064 & triticimaculans & T. aestivum & Argentina \\
\hline
\end{tabular}

(continued on next page)

a Name in bold indicates ex-type culture. 
Table 2. (continued from preceding page)

\begin{tabular}{|c|c|c|c|}
\hline Isolate no. & Alternaria sp. ${ }^{\mathrm{a}}$ & Host, substrate & Origin \\
\hline RGR 96.0066 & cetera & Elymus scabrus var. plurinervis & Queensland, Australia \\
\hline RGR 96.0075 & pseudorostrata & Euphorbia pulcherrima & New Zealand \\
\hline RGR 96.0076 & rostellata & E. pulcherrima & New Zealand \\
\hline RGR 96.0088 & tomatophila & Lycopersicon esculentum & Indiana, United States \\
\hline RGR 96.0152 & longipes & Nicotiana tabacum & North Carolina, United States \\
\hline RGR 97.0007 & sp. & M. domestica & New Zealand \\
\hline RGR 97.0008 & sp. & M. domestica & New Zealand \\
\hline RGR 97.0009 & sp. & M. domestica & New Zealand \\
\hline RGR 97.0010 & sp. & M. domestica & New Zealand \\
\hline RGR 97.0011 & sp. & M. domestica & New Zealand \\
\hline RGR 97.0012 & sp. & M. domestica & New Zealand \\
\hline RGR 97.0013 & sp. & M. domestica & New Zealand \\
\hline RGR 97.0014 & sp. & M. domestica & New Zealand \\
\hline RGR 97.0015 & sp. & M. domestica & New Zealand \\
\hline RGR 97.0016 & sp. & M. domestica & New Zealand \\
\hline RGR 97.0017 & sp. & M. domestica & New Zealand \\
\hline RGR 97.0018 & sp. & M. domestica & New Zealand \\
\hline RGR 97.0019 & sp. & M. domestica & New Zealand \\
\hline RGR 97.0020 & sp. & M. domestica & New Zealand \\
\hline RGR 97.0021 & sp. & M. domestica & New Zealand \\
\hline RGR 97.0022 & sp. & M. domestica & New Zealand \\
\hline RGR 97.0023 & sp. & M. domestica & New Zealand \\
\hline RGR 97.0024 & sp. & M. domestica & New Zealand \\
\hline RGR 97.0025 & sp. & M. domestica & New Zealand \\
\hline RGR 97.0026 & sp. & M. domestica & New Zealand \\
\hline RGR 97.0027 & sp. & M. domestica & New Zealand \\
\hline RGR 97.0044 & 'mali' & M. domestica & North Carolina, United States \\
\hline RGR 97.0045 & 'mali' & M. domestica & North Carolina, United States \\
\hline RGR 97.0046 & 'mali' & M. domestica & North Carolina, United States \\
\hline RGR 97.0047 & 'mali' & M. domestica & North Carolina, United States \\
\hline RGR 97.0067 & sp. & M. domestica & New Zealand \\
\hline RGR 98.0225 & sp. & M. domestica & Japan \\
\hline RGR 98.0227 & sp. & M. domestica & Japan \\
\hline RGR 98.0228 & sp. & M. domestica & Japan \\
\hline RGR 98.0230 & sp. & M. domestica & Japan \\
\hline RGR 98.0231 & sp. & M. domestica & Japan \\
\hline RGR 98.0272 & sp. & M. domestica & Michigan, United States \\
\hline RGR 98.0382 & mali & M. domestica & North Carolina, United States \\
\hline RGR 99.0020 & limoniasperae & Citrus reticulata $\times C$. paradisi (Mineola tangelo) & Colombia \\
\hline RGR 99.0021 & citrimacularis & C. jambhiri (rough lemon) & Florida, United States \\
\hline RGR 99.0022 & limoniasperae & C. jambhiri (rough lemon) & Lake Alfred, Florida \\
\hline RGR 99.0023 & limoniasperae & C. jambhiri (rough lemon) & Lake Alfred, Florida \\
\hline RGR 99.0024 & limoniasperae & C. jambhiri (rough lemon) & Florida, United States \\
\hline RGR 99.0025 & limoniasperae & C. jambhiri (rough lemon) & Lake Alfred, Florida \\
\hline RGR 99.0026 & tangelonis & C. reticulata $\times$ C. paradisi (Minneola tangelo) & Florida \\
\hline RGR 99.0027 & citriarbusti & C. reticulata $\times C$. paradisi (Minneola tangelo) & Lake Alfred, Florida \\
\hline RGR 99.0028 & citriarbusti & C. reticulata $\times$ C. paradisi (Minneola tangelo) & Lake Alfred, Florida \\
\hline RGR 99.0029 & tangelonis & C. reticulata $\times C$. paradisi (Minneola tangelo) & "Shinn Grove", Florida \\
\hline RGR 99.0030 & tangelonis & C. reticulata $\times$ C. paradisi (Minneola tangelo) & "Shinn Grove", Florida \\
\hline RGR 99.0031 & tangelonis & C. reticulata $\times$ C. paradisi (Minneola tangelo) & "Shinn Grove", Florida \\
\hline RGR 99.0032 & tangelonis & C. reticulata $\times$ C. paradisi (Minneola tangelo) & "Shinn Grove", Florida \\
\hline RGR 99.0033 & tangelonis & C. reticulata $\times$ C. paradisi (Minneola tangelo) & "Shinn Grove", Florida \\
\hline RGR 99.0034 & limoniasperae & C. jambhiri (rough lemon) & "BC", Florida \\
\hline RGR 99.0035 & limoniasperae & C. jambhiri (rough lemon) & Lake Alfred, Florida \\
\hline RGR 99.0036 & citrimacularis & C. jambhiri (rough lemon) & "HC", Florida \\
\hline RGR 99.0037 & citrimacularis & C. jambhiri (rough lemon) & Lake Alfred, Florida \\
\hline RGR 99.0038 & citrimacularis & C. jambhiri (rough lemon) & Lake Alfred, Florida \\
\hline RGR 99.0039 & citrimacularis & C. jambhiri (rough lemon) & Lake Alfred, Florida \\
\hline RGR 99.0040 & limoniasperae & C. jambhiri (rough lemon) & Lake Alfred, Florida \\
\hline RGR 99.0041 & tangelonis & C. reticulata $\times$ C. paradisi (Minneola tangelo) & "Shinn Grove", Florida \\
\hline RGR 99.0042 & citriarbusti & C. reticulata $\times$ C. paradisi (Minneola tangelo) & Lake Alfred, Florida \\
\hline RGR 99.0043 & tangelonis & C. reticulata $\times C$. paradisi (Minneola tangelo) & Lake Alfred, Florida \\
\hline RGR 99.0044 & tangelonis & C. reticulata $\times$ C. paradisi (Minneola tangelo) & Lake Alfred, Florida \\
\hline RGR 99.0045 & tangelonis & C. reticulata $\times$ C. paradisi (Minneola tangelo) & Lake Alfred, Florida \\
\hline RGR 99.0046 & tangelonis & C. reticulata $\times$ C. paradisi (Minneola tangelo) & Immokalee, Florida \\
\hline RGR 99.0047 & tangelonis & C. reticulata $\times$ C. paradisi (Minneola tangelo) & Immokalee, Florida \\
\hline RGR 99.0048 & toxicogenica & C. reticulata $\mathrm{cv}$. Dancy & Wauchula, Florida \\
\hline RGR 99.0049 & tangelonis & C. reticulata $\times$ C. paradisi (Minneola tangelo) & Chinchina, Colombia \\
\hline RGR 99.0050 & limoniasperae & C. jambhiri (rough lemon) & Lake Alfred, Florida \\
\hline RGR 99.0051 & limoniasperae & C. jambhiri (rough lemon) & Florida \\
\hline RGR 99.0052 & tangelonis & C. reticulata $\times$ C. paradisi (Minneola tangelo) & Chinchina, Colombia \\
\hline RGR 99.0053 & tangelonis & C. reticulata $\times$ C. paradisi (Minneola tangelo) & Chinchina, Colombia \\
\hline RGR 99.0054 & tangelonis & C. reticulata $\times C$. paradisi (Minneola tangelo) & Chinchina, Colombia \\
\hline
\end{tabular}


Table 2. (continued from preceding page)

\begin{tabular}{|c|c|c|c|}
\hline Isolate no. & Alternaria sp. ${ }^{\text {a }}$ & Host, substrate & Origin \\
\hline RGR 99.0055 & tangelonis & C. reticulata $\times C$. paradisi (Minneola tangelo) & Chinchina, Colombia \\
\hline RGR 99.0056 & limoniasperae & C. jambhiri (rough lemon) & Avon Park, Florida \\
\hline RGR 99.0057 & citriarbusti & C. jambhiri (rough lemon) & "Shinn Grove", Florida \\
\hline RGR 99.0058 & tangelonis & C. reticulata $\times C$. paradisi (Minneola tangelo) & "Shinn Grove", Florida \\
\hline RGR 99.0060 & limoniasperae & C. jambhiri (rough lemon) & Lake Alfred, Florida \\
\hline RGR 99.0061 & citrimacularis & C. jambhiri (rough lemon) & Lake Alfred, Florida \\
\hline RGR 99.0062 & limoniasperae & C. jambhiri (rough lemon) & Lake Alfred, Florida \\
\hline RGR 99.0063 & limoniasperae & C. jambhiri (rough lemon) & Lake Alfred, Florida \\
\hline RGR 99.0064 & limoniasperae & C. jambhiri (rough lemon) & "BC", Florida \\
\hline RGR 99.0065 & limoniasperae & C. jambhiri (rough lemon) & Lake Alfred, Florida \\
\hline RGR 99.0066 & citrimacularis & C. jambhiri (rough lemon) & Lake Alfred, Florida \\
\hline RGR 99.0067 & limoniasperae & C. jambhiri (rough lemon) & Lake Alfred, Florida \\
\hline RGR 99.0068 & limoniasperae & C. jambhiri (rough lemon) & Lake Alfred, Florida \\
\hline RGR 99.0069 & limoniasperae & C. jambhiri (rough lemon) & "HC", Florida \\
\hline RGR 99.0070 & limoniasperae & C. jambhiri (rough lemon) & Lake Alfred, Florida \\
\hline RGR 99.0072 & citrimacularis & C. jambhiri (rough lemon) & Lake Alfred, Florida \\
\hline RGR 99.0073 & citrimacularis & C. jambhiri (rough lemon) & Lake Alfred, Florida \\
\hline RGR 99.0074 & citrimacularis & C. jambhiri (rough lemon) & "BC", Florida \\
\hline RGR 99.0075 & citrimacularis & C. jambhiri (rough lemon) & "BC", Florida \\
\hline RGR 99.0077 & colombiana & C. reticulata $\times C$. paradisi (Minneola tangelo) & Chinchina, Colombia \\
\hline RGR 99.0078 & tangelonis & C. reticulata $\times$ C. paradisi (Minneola tangelo) & Chinchina, Colombia \\
\hline RGR 99.0082 & interrupta & C. reticulata $\times C$. paradisi (Minneola tangelo) & Israel \\
\hline RGR 99.0083 & tangelonis & C. reticulata $\times C$. paradisi (Minneola tangelo) & Chinchina, Colombia \\
\hline RGR 99.0084 & turkisafria & C. reticulata $\times C$. paradisi (Minneola tangelo) & Tzaneen, SA \\
\hline RGR 99.0085 & turkisafria & C. reticulata $\times$ C. paradisi (Minneola tangelo) & Tzaneen, SA \\
\hline RGR 99.0087 & turkisafria & C. reticulata $\times C$. paradisi (Minneola tangelo) & Tzaneen, SA \\
\hline RGR 99.0088 & tangelonis & C. reticulata $\times$ C. paradisi (Minneola tangelo) & Chinchina, Colombia \\
\hline RGR 99.0089 & turkisafria & C. reticulata $\times C$. paradisi (Minneola tangelo) & Tzaneen, SA \\
\hline RGR 99.0094 & turkisafria & C. reticulata $\times C$. paradisi (Minneola tangelo) & Israel \\
\hline RGR 99.0096 & turkisafria & C. reticulata $\times C$. paradisi (Minneola tangelo) & Israel \\
\hline RGR 99.0097 & turkisafria & C. reticulata $\times C$. paradisi (Minneola tangelo) & Israel \\
\hline RGR 99.0099 & dumosa & C. reticulata $\times C$. paradisi (Minneola tangelo) & Israel \\
\hline RGR 99.0100 & turkisafria & C. reticulata $\times C$. paradisi (Minneola tangelo) & Israel \\
\hline RGR 99.0101 & perangusta & C. reticulata $\times C$. paradisi (Minneola tangelo) & Turkey \\
\hline RGR 99.0102 & trukisafria & C. reticulata $\times$ C. paradisi (Minneola tangelo) & Turkey \\
\hline RGR 99.0103 & turkisafria & C. reticulata $\times$ C. paradisi (Minneola tangelo) & Turkey \\
\hline RGR 99.0104 & turkisafria & C. reticulata $\times C$. paradisi (Minneola tangelo) & Turkey \\
\hline RGR 99.0105 & turkisafria & C. reticulata $\times$ C. paradisi (Minneola tangelo) & Turkey \\
\hline RGR 99.0106 & turkisafria & C. reticulata $\times$ C. paradisi (Minneola tangelo) & Turkey \\
\hline RGR 99.0107 & turkisafria & C. reticulata $\times$ C. paradisi (Minneola tangelo) & Turkey \\
\hline RGR 99.0108 & turkisafria & C. reticulata $\times C$. paradisi (Minneola tangelo) & Turkey \\
\hline RGR 99.0128 & arborescens & Lycopersicon esculentum & California, United States \\
\hline RGR 99.0149 & cretica & L. esculentum & Crete, Greece \\
\hline RGR 99.0154 & nitrimali & Solanum viarum & Puerto Rico, United States \\
\hline RGR 99.0157 & tomatophila & L. esculentum & Indiana, United States \\
\hline RGR 99.0158 & grandis & S. tumerosum & Pennsylvania, United States \\
\hline RGR 99.0159 & capsici & Capiscum annuиm & Australia, IMI 262408 \\
\hline RGR 99.0161 & subcylindrica & L. esculentum var. cerasiforme & Louisiana, United States \\
\hline RGR 99.0167 & elegans & L. esculentum var. cerasiforme & Burkina Faso \\
\hline
\end{tabular}

and on the sides, but were noted most frequently at the stem end of intercepted Chinese Ya Li pear samples. Sporulation typically occurred from scattered clusters (Fig. 1B) of caespitose primary conidiophores produced from small clusters of dark subepidermal pseudoparenchymatous cells. As sporulation progressed, these clusters became continuous, forming dense stands of erect conidiophores and conidia that gave sporulating lesions a velvety appearance.

Molecular analysis. Cluster analysis of combined RAPD fragment patterns, produced using three primers in PCRs with representative isolates of Alternaria associated with lesions on Chinese Ya Li pear and with other Alternaria spp. of interest, is presented in Figure 2. Fragment patterns produced by isolates within the same morphological species were more similar to each other than to those of other species, and were clearly segregated into common clusters on this basis, as reported by Roberts et al. (15). Representative isolates from Chinese Ya Li pear intercepts clustered together in the lowermost branch of the dendrogram, but produced fragment patterns that were highly polymorphic and suggested that multiple taxa might be involved in the pathology of Chinese $\mathrm{Ya} \mathrm{Li}$ pear.

A gel representing typical results from screening of isolates with gai 2 -gai 2 and AMT primer pairs is presented in Figure 3. All isolates of A. gaisen (Tables 1 and 2) produced a single diagnostic 247-bp amplicon. The LinF1-LinR primers for the AMT gene produced a single 500-bp amplicon from DNA of apple leaf blotch pathogens currently referred to as A. mali. No Alternaria isolate from Chinese $\mathrm{Ya} \mathrm{Li}$ pear produced either the A. gaisen- or $A$. 'mali'-specific amplicons. All isolates tested produced an amplicon of expected size from the $\beta$-tubulin primers (Fig. 3, arrows), indicating that absence of gaisenor AMT-specific amplicons were not due to failed PCRs.

Morphological observations. Sporulation pattern. Isolates obtained from Chinese Ya Li pear in 2001 exhibit a distinct sporulation that differed from the patterns typical of group 1, A. gaisen, A. arborescens, A. alternata, A. tenuissima, or A. infectoria, or of the groups these taxa represent (20). The predominant sporulation pattern of the $\mathrm{Ya} \mathrm{Li}$ isolates is described here as a seventh recognizable pattern (group 7). On PCA or half-strength PCA, primary conidiophores in light-exposed areas of the culture are upright and are produced directly from the agar surface with a single apical conidiogenous locus or commonly with geniculate extensions of and frequently lateral branches from the 
primary conidiophore, resulting in multiple chain formation. The appearance of the conidia in these chains is robust, predominantly ovate to broadly obovoid, with distinct, often elongated secondary conidiophores produced at conidium apices or from lateral secondary conidiophores, the latter of which generally arise at right angles to the spore axis and undergo visible extension before producing a conidium. At 5 days, chains of four to eight conidia are common, with lateral conidial chains short (fewer than four conidia) when present. At 7 to 12 days, primary chains of 10 to 12 conidia are common, and development of secondary and tertiary lateral branches of 1 to 8 conidia is evident, producing an open but densely sporulating appearance. Production of elongated secondary conidiophores from conidium bodies becomes more apparent with age, and is more pronounced on halfstrength PCA than on PCA.

Sporulation that occurs from dark-exposed areas of the colony generally arises from short conidiophores that are borne laterally over the surfaces of erect fascicles of hyphae up to several millimeters in height, giving the appearance of a bottle brush. Conidia produced from these conidiophores are essentially similar to those produce in light-exposed areas. With certain isolates, these fascicles are quite thick and discrete; with others, they are more delicate and diffuse.

Morphometry of conidia. Isolates obtained from Chinese Ya Li pear in 2001 did

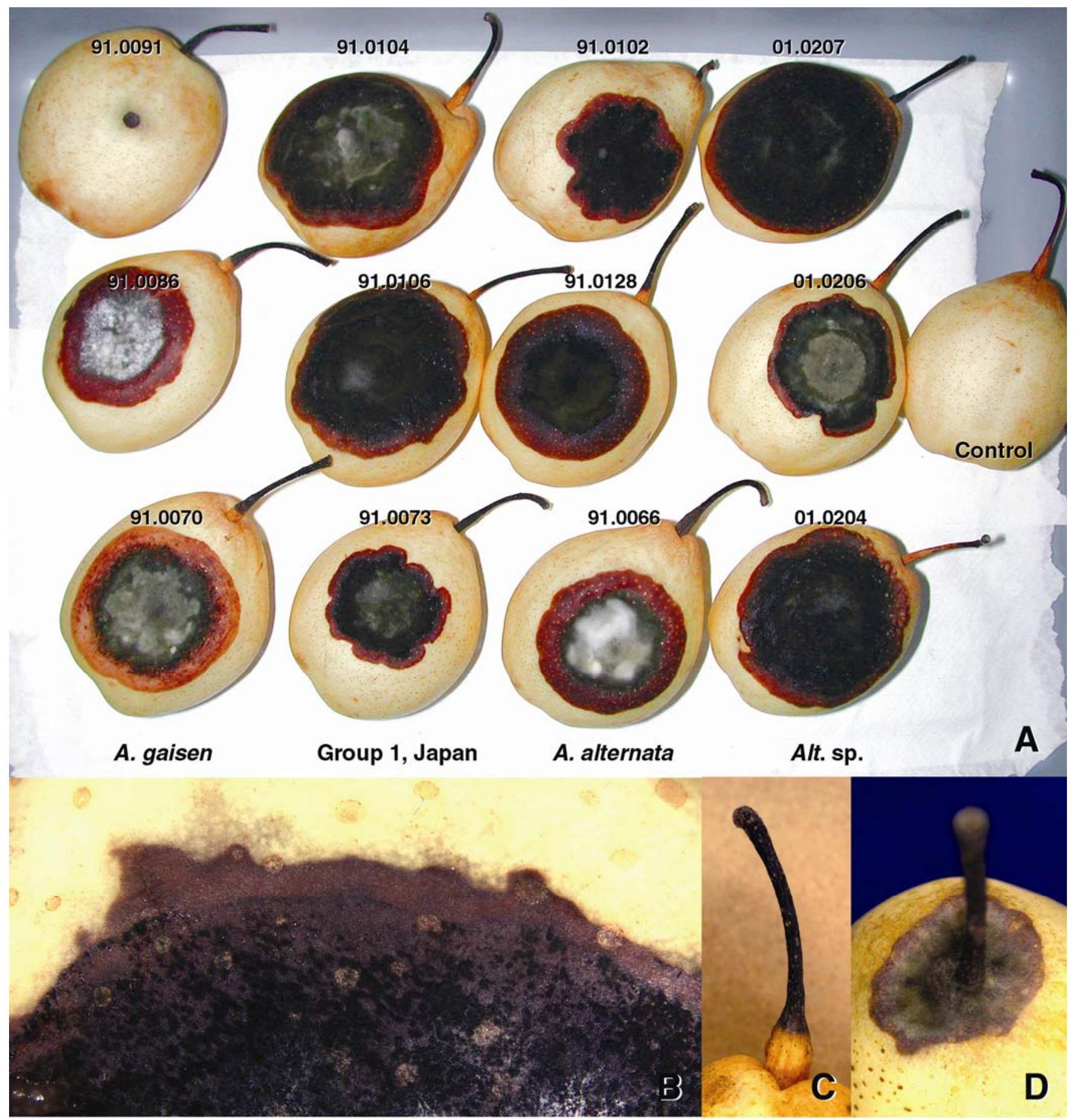

Fig. 1. Inoculated and naturally infected Ya Li pear fruit with lesions caused by Alternaria spp. A, Fruit lesions on Ya Li pear evident 14 days post inoculation. B, Detail of lesion margin and initiation of sporulation at the lesion edge. C, Natural infection of Ya Li pear stem by Alternaria spp., taken directly from a previously unopened box of Chinese Ya Li pear bought in San Francisco, CA. D, Stem-end fruit lesion caused by growth of the stem lesion in C into the fruit cortex. 
not exhibit the conidial characters typical of A. gaisen or A. alternata, or of the groups represented by these taxa (20). A brief description of a representative isolate of A. alternata and A. gaisen is presented here in reference to the subsequent description of RGR 01.0204 from Chinese Ya Li pear as a new species.

RGR 91.0102 (A. alternata) (Fig. 4, right side): conidia observed from host tissues 19 days post inoculation were obclavate to short cylindrical, and occasionally constricted at median septa (Fig. 4, lower right). Spore surfaces were minutely to coarsely verrucose. Upper ranges for spore body measurements were 32.7 to 54.0 by 13.3 to $16.2 \mu \mathrm{m}$. Single or multiple, often geniculate secondary conidiophores measured 4.5 to 24.3 by 3.2 to 5.7 $\mu \mathrm{m}$. Conidia in branched chains produced on PCA after 7 to 10 days varied from ellipsoidal to ovate to obclavate, with the upper range for spore body measurements 23.1 to 38.1 by 9.8 to $13.1 \mu \mathrm{m}$ (Fig. 4, upper right). In culture, secondary conidiophores that grew from spore apices or bodies frequently were less geniculate than those produced on host tissue. Secondary conidiophores measured 3.1 to 9.3 by 3.2 to $4.5 \mu \mathrm{m}$, and produced the dense secondary, tertiary, and quaternary spore chains without extensive primary spore chain elongation that gives sporulation of $A$. alternata its distinctive "bushy" appearance, a pronounced character when grown on Hay agar (20).

RGR 91.0070 (A. gaisen) (Fig. 4, left side): conidia observed from host tissues 19 days post inoculation were obclavate to short cylindrical, and occasionally constricted at median septa (Fig. 4, lower left). Spore surfaces were minutely to coarsely verrucose. Upper ranges for spore body measurements were 28.2 to 117.5 by 10.9 to $39.2 \mu \mathrm{m}$. Secondary conidiophores were simple, cylindrical, often widening appreciably at their bases, and measured 3.2 to 98.6 by 2.1 to $21.5 \mu \mathrm{m}$.

Conidia produced on PCA after 7 to 10 days were in primarily unbranched chains and varied from ellipsoidal to cylindrical; the upper range for spore body measurements was 29.0 to 118.7 by 8.5 to $28.5 \mu \mathrm{m}$ (Fig. 4, upper left). On PCA, secondary conidiophores produced at spore apices were simple, often rudimentary, nongeniculate, and measured 2.2 to 28.0 by 3.2 to $8.9 \mu \mathrm{m}$.

Taxonomy. The morphological, pathological, and genetic characteristics of the Alternaria isolates obtained from intercepted Chinese Ya Li pear clearly differentiate them from A. alternata, A. gaisen, and other species known to occur commonly on pome fruit or other substrates. As an example, for RGR 01.0204, the

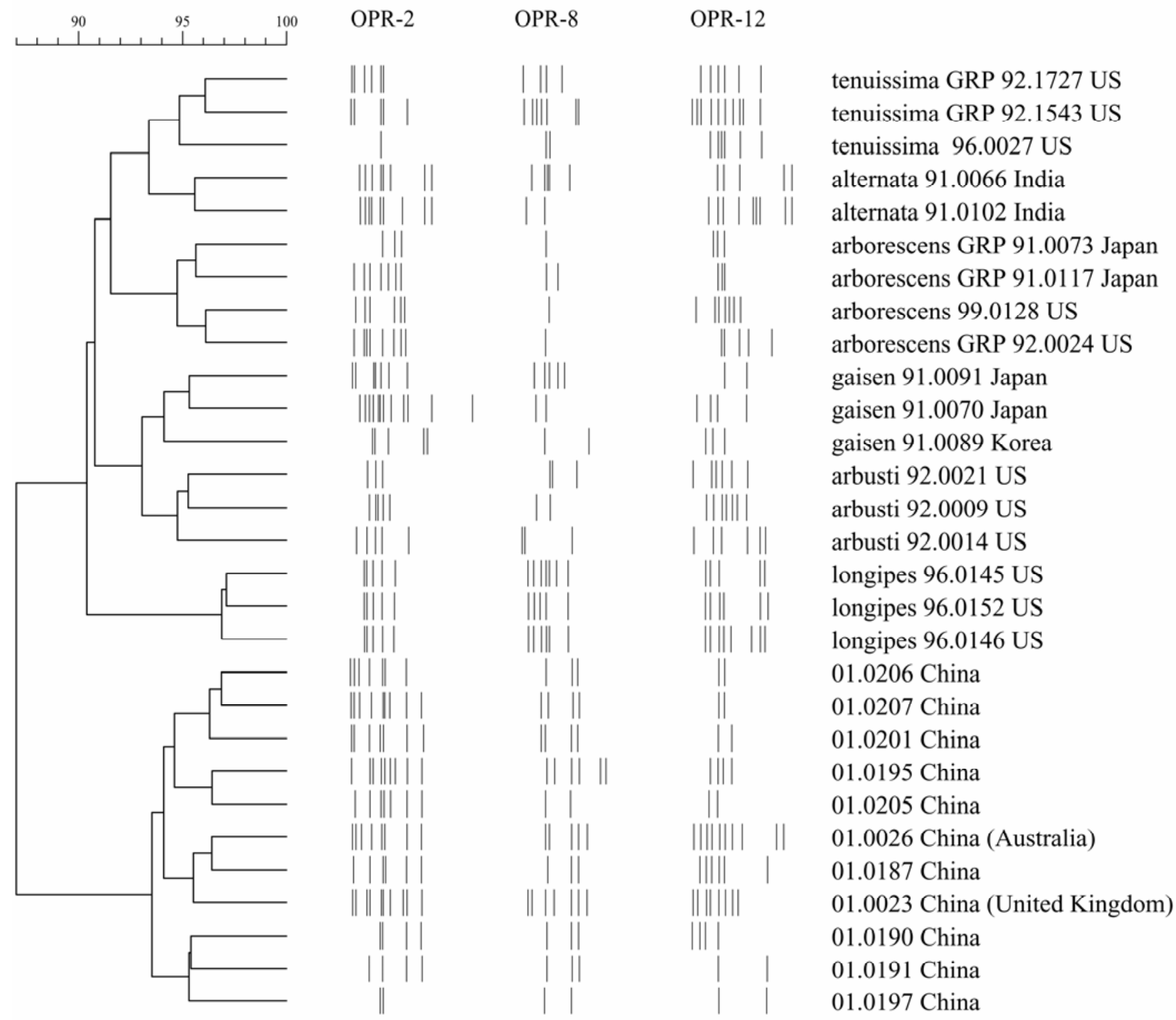

Fig. 2. Dendrogram representing the cluster analysis and percentage relatedness of random amplified polymorphic DNA fragment patterns produced with primers OPR-2, OPR-8, and OPR-12, using the Ward algorithm and the Fuzzy Logic coefficient in GelCompar 4.1. 
widely branching chains of robust, beakless conidia usually 12 or fewer in length reported in this article; the lack of short, bushy sporulation on Hay agar (as in $A$. alternata) (20); the lack of amplicons from phytotoxin-specific PCR reactions (AKT [A. gaisen] and AMT [A. 'mali']; Table 1); and the RAPD fragment patterns (Fig. 2) (15) distinguish it from A. gaisen, A. alternata, A. arborescens, A. tenuissima, A. infectoria, A. arbusti (20), and any other taxon known to the author. Additionally, the disease caused by the $\mathrm{Ya} \mathrm{Li}$ isolates does not resemble black spot of Japanese pear (caused by A. gaisen), and is distinctly different from any pear disease known in the United States or described in the available literature. For this reason, RGR 01.0204 is described as the type of a new species, A. yaliinficiens. A. yaliinficiens also is represented by additional isolates in the author's (RGR) culture collection; all were isolated from lesions on intercepted Chinese Ya Li pear fruit.

Alternaria yaliinficiens R. G. Roberts, sp. nov. (Fig. 5)

Etym.: yali-, latinization of the cultivar name 'Ya Li'; + inficiens, infecting

Ex carne fructus hospitis et agaro PCA descripta. In hospite: conidiophora simplicia vel parce ramosa, atrofusca, ad 75$108 \times 5-6 \mu m$, ex pulvinulis erumpentibus cellularum stromaticarum atropigmentosarum prodientes. Conidia solitaria vel catenulata usque ad 5 sporas, late ovoidea vel cylindrica, laevia vel verrucosa, septis constrictis. Conidia ad ca. 40.1-70.3 $\times$ 16.3-21.2 $\mu \mathrm{m}$; conidiophora secondaria apicalia vel rare lateralia 2.1-22.3 × 2.8$4.5 \mu \mathrm{m}$. In PCA: conidiophora primaria erecta, simplicia vel ramosa, locis conidiogenis singulis vel multiplicibus sympodialibus. Conidiophora proximalia hyalina, distalia fusca. Catena primitus eramosa; mox (7-10 d) plerumque ramosa, conidiis ca. 10 ellipsoideis, ovoideis, vel late obclavatis. Conidia erostrata sed conidiophoris secondariis apicalibus vel lateralibus, simplicibus vel geniculatis, 6.0-41.0 × 3.3-8.5 $\mu \mathrm{m}$. Conidia ad ca. 27.1-46.5 × 11.0-16.6 $\mu \mathrm{m}$, in 1-2 septis medianis atropigmentosis constricta.

Habitatio typi in laesione fructus Pyrus bretschneideri Rehder. Distributio cognita Hebei Prov., China. Holotypus: pars ex cultura RGR 01.0204 desiccata et in BPI conservanda (BPI 844246).

On pear fruit inoculated and held 19 days post inoculation under alternating cycles of light $(8 \mathrm{~h})$ and dark $(16 \mathrm{~h})$, conidia are produced from simple or branched conidiophores with an upper range of 75 to 108 by 5 to $6 \mu \mathrm{m}$ that arise from clusters of erumpent, deeply pigmented stromatic cells resembling microsclerotia (Fig. 5, bottom center). Conidia are produced singly or in short, usually unbranched chains of two to three spores, or occasionally as sort-branched chains of similar length. Conidia are variable in
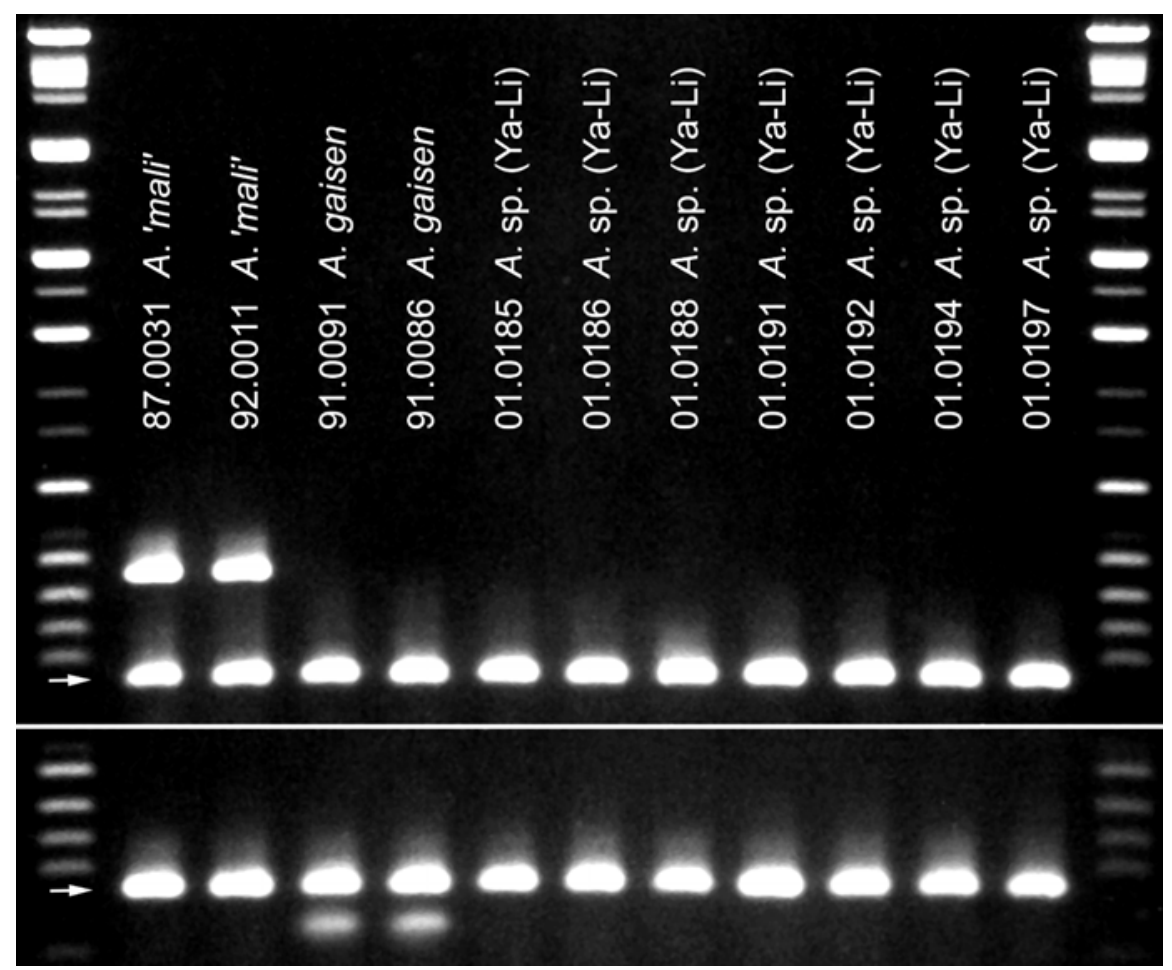

Fig. 3. Representative illustration of species-specific polymerase chain reaction screening of Alternaria isolates from Ya Li pear and representative isolates of A. gaisen and A. 'mali'. A. 'mali' isolates produced a 500-bp product with the LinF1/LinR primer set, A. gaisen isolates produced a 247-bp product with the gaif2/gair2 primer set, and all isolates from $\mathrm{Ya} \mathrm{Li} \mathrm{pear} \mathrm{produced} \mathrm{no} \mathrm{amplicons} \mathrm{with}$ either primer set. All isolates produced a 350-bp product with $\beta$-tubulin primers (arrows). Water controls produced no bands (not pictured). shape from broadly oval to cylindrical, deeply constricted at one to three deeply pigmented septa, and often constricted without pigmentation at other septa to give a bulbous appearance to individual cells and a sinuous outline to the spore body (Fig. 4D and Fig. 5, bottom panel). The upper range of spore body measurements is 40.1 to 70.3 by 16.3 to $21.2 \mu \mathrm{m}$. Single apical or, rarely, lateral multiple secondary conidiophores measure 2.1 to 22.3 by 2.8 to $4.5 \mu \mathrm{m}$.

Colonies exhibit concentric rings of growth corresponding to the alternating exposure to light (dark rings of culture) and dark (light rings of culture) on V8, PCA, half-strength PCA, and Hay agars, in descending order of sporulation density.

On PCA, primary conidiophores in light-exposed areas from 48 to 140 by 3.3 to $5.3 \mu \mathrm{m}$, erect, unbranched or branched, with single or multiple conidiogenous loci arising via sympodial growth of the primary conidiophore. Conidiophores are proximally hyaline, becoming pigmented distally in varying shades of grayish brown. Conidial chains from a single locus initially are unbranched; however, by 3 days of growth, branched chains up to 5 spores in length are evident and, by 7 to 10 days, branched chains of up to 10 ellipsoidal, ovate, to broadly obclavate conidia predominate. Like those from host tissue, conidia produced in culture are beakless, but chain formation occurs via the production of relatively long, occasionally geniculate secondary conidiophores, 6.0 to 41.0 by 3.3 to $8.5 \mu \mathrm{m}$, that arise apically and laterally from conidium bodies. The nearly right angle of branching and the relatively long secondary chains produced from intercalary cells give cultures observed at $\times 50$ magnification an open but tangled appearance. The largest conidia measure 27.1 to 46.5 by 11.0 to $16.6 \mu \mathrm{m}$ and are constricted at one to two deeply pigmented median septa (Fig. 2B). The upper portions of some conidia occasionally become elongated and develop a tapered appearance that might be confused with a beak, but these conidia are neither truly rostrate nor diagnostic for this species.

On half-strength PCA, sporulation is much sparser and the zonate character of the colony is much less pronounced than on PCA. Secondary conidiophores produced on half-strength PCA tend to be more abundant and longer, but the appearance is otherwise similar to that described from PCA.

On Hay agar, sporulation is sparse, with solitary or branched conidiophores arising directly from the agar surface. Chains of 10 or (usually) fewer conidia form that are unbranched or branched, pale straw in color, smooth to verruculose, fusiform to narrowly ellipsoidal, the upper spore body frequently tapering; at 9 days, upper ranges of spore measurements were 37.3 to 51.3 by 9.4 to $12.3 \mu \mathrm{m}$. 
On V8 juice agar, sporulation is so dense that the pattern of sporulation cannot be determined. Conidia produced on V8 are more heavily pigmented, but otherwise similar those produced on PCA, measuring 37.7 to 55.4 by 11.7 to $15.0 \mu \mathrm{m}$.

\section{DISCUSSION}

The 2001-02 import experience with Chinese $\mathrm{Ya} \mathrm{Li}$ pear provided a compelling rationale for the importance of accurate identification of plant-pathogenic fungi and the diseases they cause on internationally traded commodities. This experience also emphasizes the need to base mitigative measures upon sound, scientific knowledge of the identity and epidemiology of the pathogen and disease. Inoculation studies with and molecular characterization of isolates cultured from intercepted fruit have demonstrated that $\mathrm{Ya} \mathrm{Li}$ pear fruit are highly susceptible to infection by multiple Alternaria spp., and that the decay observed on fruit intercepts from China can represent mixed infections by more than one taxon. Although the Chinese Ya Li pear fruit obtained commercially for inoculation studies were imported under a work plan that contained mitigative measures for black spot $(A$. gaisen) and A. alternata, nearly $100 \%$ of the fruit exhibited stem lesions from which Alternaria isolates were obtained and for which neither of these names can be correctly applied.

Although the import program has continued to operate since 2001 on an irregular basis, we are still confronted with a disease of unknown epidemiology that involves multiple pathogens causing disease originating at fruit stems, calyxes, and cortices, and for which we have a near total lack of scientific evidence upon which to base mitigative measures. This is more than an academic issue because $\mathrm{Ya} \mathrm{Li}$ pear fruit are produced in the United States and no disease with these symptoms and involving these pathogens is known in the United States on fruit of any pear cultivar $(5,8)$. A comparison and description of the entire Alternaria isolate set from $\mathrm{Ya} \mathrm{Li}$ pear is beyond the scope of this article. Additional isolates have been obtained each year since 2001; the nature and identity of these will be addressed separately. It should be stated, however, that none of the isolates obtained in 2001 or in subsequent years possess the morphological or genetic characters that indicate conspecificity with either A. gaisen or A. alternata.

The practice of using the name A. alternata for essentially all small-spored plantpathogenic or saprophytic Alternaria spp. (and thereby circumventing any possible phytosanitary issue preventing the importation of exotic diseases) may seem innocuous if not incorrect, but one need only to look at the export of black spot disease of Japanese pear to Italy (9) and France (3) on infected nursery stock from Japan to see the practical and negative impact of this practice on production agriculture. Kohmoto et al. (9) referred to the pathogen in Italy as A. alternata "Japanese pear pathotype" and Baudry (3) referred to the pathogen in France as A. kikuchiana; in both cases, the correct pathogen name is $A$. gaisen, a fungus which prior to these reports was unknown outside of the Orient.

The (mis)use of the name A. alternata in association with the black spot pathogen of Japanese pear and other Alternaria spp. (A. longipes, A. mali, A. citri, and others) began with Nishimura (11), who asserted that "...these fungi look similar in conidial morphology, and statistically the measurements of conidial size come within a category of the description of a collective species Alternaria alternata (Fries) Keissler, as described by Simmons (16)." Beyond the misattribution of a nebulous "collective species" to Simmons, Nishimura further stated that "...No other significant differences to distinguish among these fungi have been established to date" and then asserted that the "...name Alternaria alternata should be adopted for these fungi, independently of their pathogenicity." These statements or variations of them have been repeated without apparent reexamination in virtually every subsequent paper that has reported research on Alternaria spp. that produce phytotoxins. In their discussion of Alternaria citrus pathogens, Akimitsu et al. (1) wrote, "The fungi causing these three diseases are smallspored, morphologically similar and are considered to be the same species, A. alternata. However, there are clear biological, biochemical and genetic differences among these fungi and they can only be differentiated using pathogenicity tests, toxin assays or genetic markers." The latter sentence is in conflict with historical facts presented in Simmons's collaborative treatment of the same citrus isolate set studied in Peever et al. (12), in which he segregated 122 isolates into morphologic groups and, from these, described 10 new species. Although these new species were largely congruent with the molecular groupings reported in Peever (12), the outliers, whether they represent aberrant isolates or simply misidentification, were used to justify referring to the entire set as A. alternata. To do so is, of course, the authors' prerogative, but to maintain that the citrus pathogens cannot be identified using morphological characters $(12,13)$ is an error of fact that ignores the weight of experimental evidence to the contrary (18). The disparity between these oft-repeated introductory statements and the experimental facts are fully disclosed in the "Facts vs. Fiction" section of Simmons's 1999 review of the issue (19). Applying the same criteria (e.g., spore size range) could lead one to identify $A$. yaliinficiens as $A$. alternata, but to do so would ignore the obvious, more predictive differences in sporulation pattern, spore shape, manner of chain elongation, cultural characters, and molecular characters that distinguish it from A. alternata.

Uncertainty remains about the relationship between the disease on intercepted Chinese Ya Li pear fruit and those reported and discussed in the early twentieth-century literature. Tanaka (22) reported that the black spot pathogen of Japanese pear was unable to cause infection on leaves and fruit of Chinese pear cultivars, including $\mathrm{Ya} \mathrm{Li}$, a result consistent with the inoculation of $\mathrm{Ya} \mathrm{Li}$ reported here with $A$. gaisen RGR 91.0091 from Japan (Fig. 1A), an isolate referenced widely in the phytotoxin literature. Isolates of A. gaisen from Korea and Taiwan, however, did cause infection of Ya Li fruit, although the symptoms produced differed from those obtained with Alternaria isolates from Ya Li pear. Tanaka also reported that there were morphological differences between Miura's fungus and the black spot pathogen, and concluded that two different fungi and diseases were involved in the pathology of Chinese and Japanese pear, and published the name A. kikuchiana for the black spot pathogen. The fruit symptoms and sign of black spot of Japanese pear include a fruit lesion that appears early in fruit development, is shiny and black in appearance and, in advanced stages, causes deeply cruciate cracks in the fruit cortex that often are filled with dark gray mycelium and sporulation of A. gaisen (8). Foliar lesions caused by $A$. gaisen typically exhibit a chlorotic halo around the necrotic lesion (8). The appearance of Alternaria spp. lesions on Ya Li pear are quite different, being chocolate brown in color, not associated with any cracking of the fruit cortex, and often associated with stem lesions (Fig. 1). The fruit and foliar lesions of $\mathrm{Ya} \mathrm{Li}$ pear figured by Zhang (Fig. 5, plate III) (27) and attributed to infection by $A$. gaisen do not exhibit the characteristic and diagnostic appearance of black spot lesions on Japanese pear fruit and leaves (8), but the fruit symptoms are nearly identical to those observed on intercepted Chinese Ya Li pear fruit caused by A. yaliinficiens (Fig. 1) and other Alternaria spp. The Alternaria sp. disease of Ya $\mathrm{Li}$ pear, caused by $A$. yaliinficiens and other Alternaria spp., hereafter will be referred to as "chocolate spot of $\mathrm{Ya} \mathrm{Li}$ pear" to distinguish it from black spot of Japanese pear, which has been recognized since the 1930 s as being a different disease with a different etiologic agent than that observed on Ya Li pear. As noted by Simmons (17), none of the early workers (Nagano, Miura, or Tanaka) designated type specimens or established cultures that can be linked directly to them. The morphological, genetic, and pathological differences noted here between $A$. gaisen and $A$. yaliinficiens suggest that Muira's Alternaria pathogen of Chinese pear and $A$. 


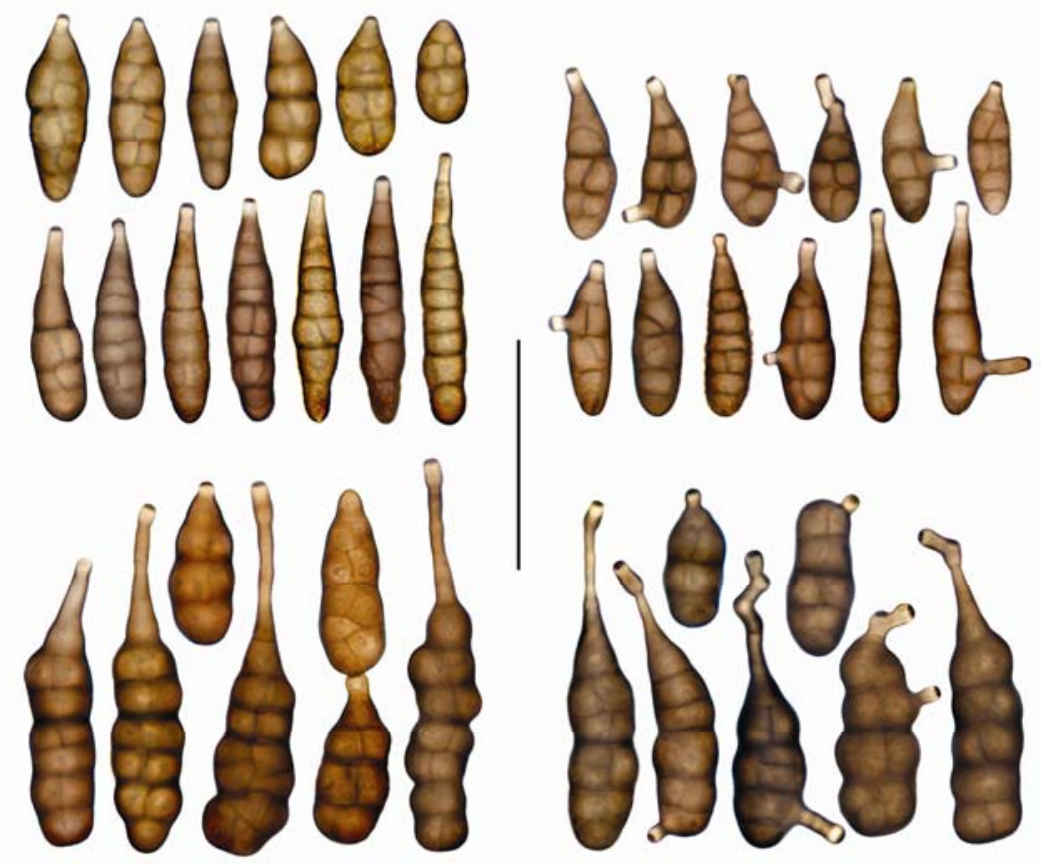

Fig. 4. Morphology of conidia of Alternaria gaisen RGR 91.0070 (left) and A. alternata RGR 91.0102 (right) from 7- to 10-day-old potato carrot agar culture (above) and from Ya Li pear 19 days post inoculation (below). Bar $=50 \mu \mathrm{m}$. yaliinficiens might be conspecific. For nomenclatural reasons also discussed in Simmons (17), none of the names used by Miura (Macrosporium nashi, A. nashi, or A. bokurai) can be correctly applied to any Alternaria sp., so description of A. yaliinficiens as a pathogen of Ya Li pear is warranted.

\section{ACKNOWLEDGMENTS}

I thank E. G. Simmons for the Latin diagnosis, critical review and comment, and continuing encouragement; M. E. Palm for the facilitation of many aspects of this study and thoughtful review;

S. Reymond for excellent technical support; M. Guidiciepietro for supplying fruit for inoculation studies; P. McGowan for supplying interception data and other information; T. Y. Zhang for the generous gift of his book; and S. Zhang for her timely partial translation of Zhang's book.

\section{LITERATURE CITED}

1. Akimitsu, K., Peever, T. L., and Timmer, L. W. 2003. Molecular, ecological and evolutionary approaches to understanding Alternaria diseases of citrus. Mol. Plant Pathol. 4:435-446.

2. Anonymous. 1994. Pear (Pyrus bretschneideri Rehd., P. serotina Rehd., P. ussuriensis Max., P. communis L.) pests: fungi. Pages 643-651 in: Harmful Pests of China Fruit Trees, 2nd ed. China Agriculture Press, Beijing.

3. Baudry, A., Morzieres, J. P., and Larue, P.

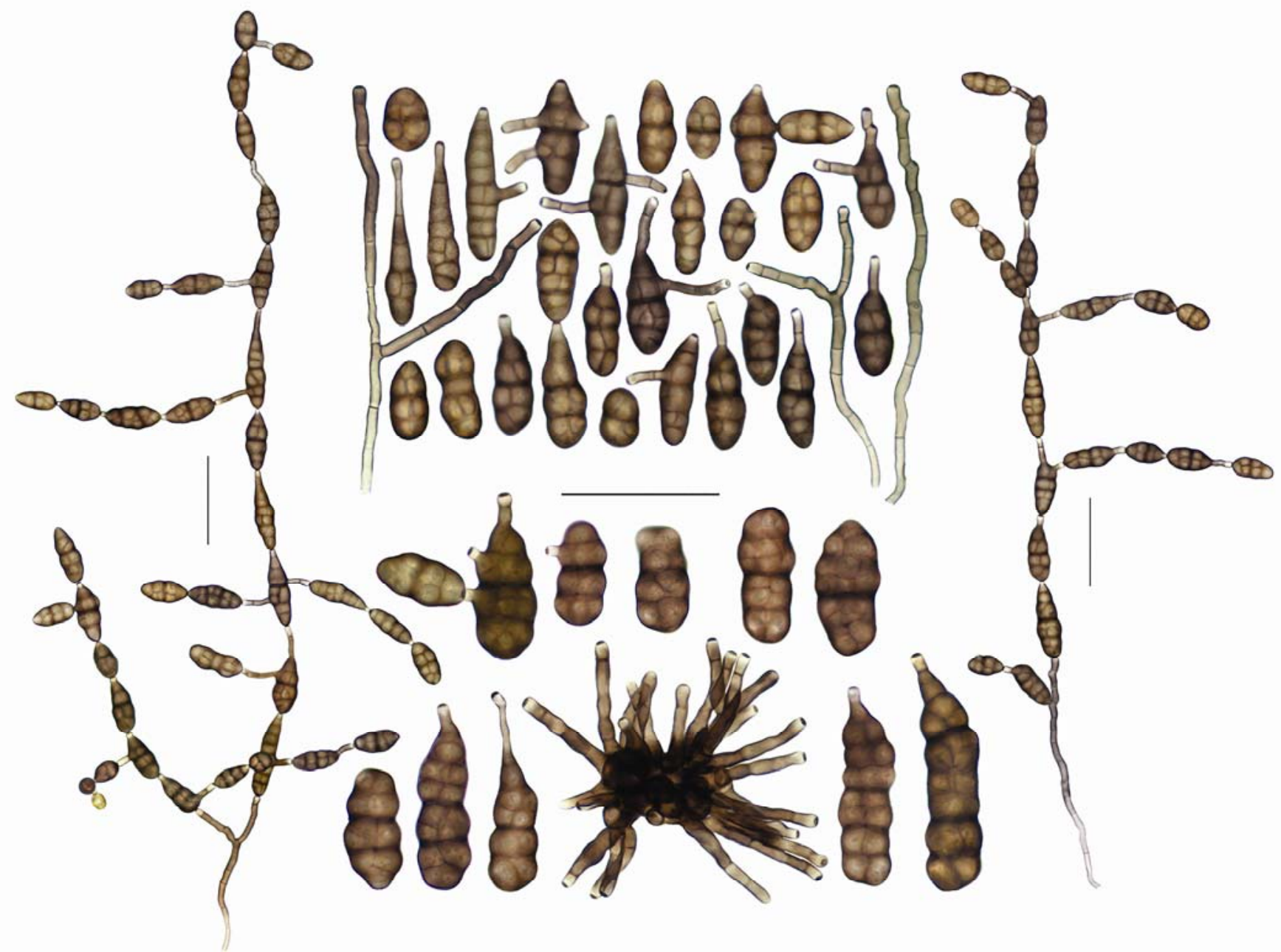

Fig. 5. Morphology of conidia, conidiophores, and sporulation pattern of Alternaria yaliinficiens RGR 01.0204 from 7- to 10-day-old potato carrot agar culture (above) and from inoculated Ya Li pear 19 days post inoculation (below). Bars $=50 \mu \mathrm{m}$. 
1993. First report of Japanese pear black spot caused by Alternaria kikuchiana in France. Plant Dis. 77:428.

4. Cave, G. L., and Lightfield, J. W. 1997. Importation of fragrant and Ya pear fruit from China into the United States: A supplemental pest risk assessment. U.S. Dep. Agric., Washington, DC.

5. Farr, D. F., Bills, G. F., Chamuris, G. P., and Rossman, A. Y. 1989. Fungi on Plants and Plant Parts in the United States. American Phytopathological Society, St. Paul, MN.

6. Greuter, W., McNeill, J., Barrie, F. R., Burdet, H.-M., Demoulin, V., Filgueiras, T. S., Nicolson, D. H., Silva, P. C., Skog, J. E., Trehane, P., Turland, N. J., and Hawksworth, D. L., eds. 2000. International Code of Botanical Nomenclature (St Louis Code). Regnum Vegetabile 138. Koeltz Scientific Books, Königstein, Germany.

7. Johnson, R. D., Johnson, L., Kohmoto, K., Otani, H., Lane, C. R., and Kodama, M. 2000. A polymerase chain reaction-based method to specifically detect Alternaria alternata apple pathotype (A. mali), the causal agent of Alternaria blotch of apple. Phytopathology 90:973976.

8. Jones, A. L., and Aldwinckle, H. R., eds. 1990. Compendium of Apple and Pear Diseases. American Phytopathological Society, St. Paul, $\mathrm{MN}$.

9. Kohmoto, K., Otani, H., Cavanni, P., and Bugiani, R. 1992. Occurrence of the Japanese pear pathotype of Alternaria alternata in Japanese pear orchards in Italy. Phytopathol.
Mediterr. 31:141-147.

10. Miura, M. 1928. Flora of Manchuria and East Mongolia. Part III. Cryptogams, fungi. South Manchurian Railway Company Ind. Proc. 27:513-515.

11. Nishimura, S. 1980. Host specific toxins from Alternaria alternata. Problems and prospects. Proc. Jpn. Acad. 56:362-366.

12. Peever, T. L., Canihos, Y., Olsen, L., Ibañez, A., Liu, Y.-C., and Timmer, L. W. 1999. Population genetic structure and host specificity of Alternaria spp. causing brown spot of Minneola tangelo and rough lemon in Florida. Phytopathology 89:851-860.

13. Peever, T. L., Su, G., Carpenter-Boggs, L., and Timmer, L. W. 2004. Molecular systematics of citrus-associated Alternaria species. Mycologia 96:119-134.

14. Roberts, J. W. 1914. Experiments with apple leaf-spot fungi. J. Agric. Res. 2:57-66.

15. Roberts, R. G., Reymond, S. T., and Andersen, B. A. 2000. RAPD fragment pattern analysis and morphological segregation of small-spored Alternaria species and species-groups. Mycol. Res. 104:151-160.

16. Simmons, E. G. 1967. Typification of Alternaria, Stemphylium and Ulocladium. Mycologia 59:67-92.

17. Simmons, E. G. 1993. Alternaria themes and variations (63-72). XI. Alternaria gaisen and the black spot disease of Japanese pear. Mycotaxon 48:91-107.

18. Simmons, E. G. 1999. Alternaria themes and variations (226-235). Classification of Citrus pathogens. Mycotaxon 70:263-323.
19. Simmons, E. G. 1999. Alternaria themes and variations (236-243). Host-specific toxin producers. Mycotaxon 70:325-369.

20. Simmons, E. G., and Roberts, R. G. 1993. Alternaria themes and variations (73). XII Morphology and toxigenicity of Alternaria associated with black spot disease of Japanese pear. Mycotaxon 48:109-140.

21. Tanaka, A., Shiotani, H., Yamamoto, M., and Tsuge, T. 1999. Insertional mutagenesis and cloning of the genes required for biosynthesis of the host-specific AK-toxin in the Japanese pear pathotype of Alternaria alternata. Mol Plant-Microbe Interact. 12:691-702.

22. Tanaka, S. 1933. Studies on black spot disease of the Japanese pear. Mem. Coll. Agric. Kyoto Imp. Univ. 28:1-35.

23. Tsuge, T., Kobayashi, H., and Nishimura, S. 1989. Organization of ribosomal RNA genes in Alternaria alternata Japanese pear pathotype, a host-selective AK-toxin-producing fungus. Curr. Genet. 16:267-272.

24. Welsh, J., and McClelland, M. 1990. Fingerprinting genomes using PCR with arbitrary primers. Nucleic Acids Res. 18:7213-7218.

25. Williams, J. G. K., Kubelik, A. R., Livak, K. J., Rafalski, J. A., and Tingey, S. V. 1990. DNA polymorphisms amplified by arbitrary primers are useful as genetic markers. Nucleic Acids Res. 18:6531-6535.

26. World Trade Organization. 2004. Sanitary and phytosanitary measures: Text of the agreement. World Trade Organization, Geneva.

27. Zhang, T. Y. 2003. Flora Fungorum Sinicorum, Vol. 16: Alternaria. Science Press, Beijing. 